Int. J. Odontostomat., 9(1):65-72, 2015.

\title{
Shape and Symmetry of Human Condyle and Mandibular Fossa
}

\author{
Forma y Simetría del Cóndilo Humano y Fosa Mandibular
}

\author{
Eduardo Cotecchia Ribeiro*; Monique Lalue Sanches * ; Luis Garcia Alonso* * * Ricardo Luiz Smith* * *
}

RIBEIRO, E. C.; SANCHES, M. L.; ALONSO, L. G. \& SMITH, R. L. Shape and symmetry of human condyle and mandibular fossa. Int. J. Odontostomat., 9(1):65-72, 2015.

ABSTRACT: The aim of the study was to determine and classify the shape of the mandibular fossa and the corresponding condyle in different types, relating them to sex and symmetry, in adult human skulls, from lateral, posterior and superior views. The sample included 50 human skulls from 23 to 82 years old, 32 males and 18 females. The condyle and silicone casting molds of the fossa were photographed to assess shape in the three views. Shapes were classified, validated by intra- and inter-rater analysis and frequency, sex distribution and symmetry verified. Shapes were classified as rounded, angled, flattened and mixed types in the lateral and posterior views; and as biconvex, flat-convex, biflattened and mixed in the superior view. Rounded condyle and fossa were more frequent in the lateral (57\% and $66 \%$ respectively) and posterior (53\% and $83 \%$ ) views. In the superior view, mixed shape presented higher frequency in condyle $(59 \%)$ while in fossa the biconvex shape (46\%) was most common. There was no significant difference in shape distribution by sex. The same shape (symmetry) or otherwise (non-symmetry) in right and left side condyle and fossa were separately assessed and showed various combinations.

KEY WORDS: temporomandibular joint, condyle, mandibular fossa, anatomy, shape, symmetry.

\section{INTRODUCTION}

The temporomandibular joint (TMJ) is a complex, highly specialized joint, and there is nothing comparable in the human skeleton. Anatomical knowledge of the $T M J$ is one of the foundations of clinical practice, allowing understanding pathological alterations, diagnostic evaluation through the resources of image diagnostics, and choice of appropriate therapeutic paths.

Among the anatomic characteristics is the presence of an articular disk which guarantees geometrical adaptation between joint faces. This disk of dense connective tissue totally divides the joint cavity in upper compartment, where translational and lateral movements take place through sliding, and lower compartment, where rotational movement takes place. These two compartments are morphologically and functionally independent.
The bone components of TMJ need careful study and understanding for the simple reason that changes in them imply functional disorders (temporomandibular disorders - TMD) and pain, that are widely discussed in the literature.

The large topographical variability between the condyle and fossa is affected by the shape of the former which suffers changes due to bone remodelment. In the absence of condyle the fossa remains shallow, maintaining the characteristics found in a newborn (Pandis et al., 1991).

When there is congenital bilateral condyle absence, morphogenesis constantly functions in seeking architectonic balance among the isolated parts (Enlow \& Hans, 2002).

\footnotetext{
Associate Professor, Department of Morphology, Universidade Federal de São Paulo, São Paulo, Brazil.

** Preceptor, Department of Morphology, Universidade Federal de São Paulo, São Paulo, Brazil.

"** Adjunct Professor, Department of Morphology, Universidade Federal de São Paulo, São Paulo, Brazil.

***** Professor, Department of Morphology, Universidade Federal de São Paulo, São Paulo, Brazil.
} 
Most authors discussing the anatomical (reciprocal position) and functional relation between condyle and fossa, including during development, generically consider the fossa with a rounded shape or, even, as being simply a depression in the squamous part of the temporal bone where the condyle articulates (Moore \& Dalley, 2007), without seeking to classify different shapes. Descriptions and consequential classifications of the fossa shape are rare in the literature. A few authors have examined condyle and fossa morphology in computed tomography (CT) images obtained from patients with TMD and non-patients, describing four fossa shapes (Raustia \& Pyhtinen, 1990). Others have analyzed the shape and location of the fossa and its relation with mandibulofacial asymmetry by means of dry-skull Xrays (Pirttiniemi \& Kantomaa, 1992). One author described the fossa as deeply concave sagitally, slightly concave transversally and wider laterally (Gray et al., 1995).

This has not been the case for condyle, where shape classification has been presented by numerous authors. There have been studies through the direct method in dry skulls (Yale et al., 1963; 1966; Mongini, 1977; Matsumoto \& Bolognese, 1995); dry-skull Xrays (Yale, 1969; Pandis et al.) and others on mandibles obtained from autopsy (Takenoshita, 1982); CT in patients with TMD, related to remodelation with dental abrasion (Mongini), in healthy individuals (Christiansen et al., 1987), and in patients with TMD and non-patients (Raustia \& Pyhtinen).

Viewing the bibliographic search, the scarcity of works related to the specific theme proposed and the morphological and clinical interest that the TMJ excites, we were able to define the objective of the present study, to wit, determine and classify the mandibular fossa and corresponding condyle shape for different types as regards sex and symmetry in adult human skulls from lateral, posterior and superior views.

\section{MATERIAL AND METHOD}

The sample consisted of 50 adult human skulls (23 to 82 years old), with 32 male and 18 female, without designation relative to ethnic group, and belonging to Museum of Anatomy Collection of the Federal University of Sao Paulo - Paulista School of Medicine (UNIFESP-EPM). The study was approved by the Research Ethics Committee at UNIFESP-EPM with the 0080/02 protocol number.
Skulls were selected randomly from the 440 in the collection. Inclusion criteria were: specimen integrity; absence of evident deformations or identified pathologies; and the presence of teeth or dental alveoli.

The condyle and mandibular fossa of skulls were evaluated for shape. Right and left condyle were photographed (Sony digital camera -- Mavica ${ }^{\circledR}$ - FD 90), maintaining a fixed distance of $30 \mathrm{~cm}$ in the lateral, posterior and superior views. Molds of the corresponding right and left fossa were obtained using silicon (Otoform R/C - dimethylpolysiloxane). Then molds representing the fossa impressions were photographed in the same manner as the condyle in the same positions.

Our findings were based on the analysis of different shapes, whose evaluation was considered the structure profile (condyle and fossa mold) according to a geometric criterion.

In the lateral and posterior views, the shapes classified were:

Rounded - profile predominance of a circumferential arch;

Angled - profile slope at acute angle;

Flattened - predominance of flattened profile ("straight");

Mixed - combination of the previous or irregular.

In the superior view, the shapes classified were:

Biconvex - convex anterior and posterior borders;

Flat-convex - flat anterior border ("straight") and convex posterior;

Biflattened - anterior and posterior borders flat ("straight");

Mixed - combination of the previous or irregular.

Intra- and inter-rater analyses were used to check observations, involving a blind evaluation of the shape of the 100 condyles and the 100 corresponding fossa molds by the researcher at two distinct times, and then by another professor of Anatomy. Statistical analysis of the intra- and inter-rater observations was done with Chi squared test, through a linear correlation to verify the extent of association and using a $5 \%$ level of significance.

A descriptive, non-parametric statistical test (Chi squared) was used for analysis of variables, considering a $5 \%$ level of significance (Siegel \& Castellan Jr., 2006). 


\section{RESULTS}

Findings refer to the classification of the shapes of the condyle and fossa molds, intra- and inter-rater analyses, shape frequencies, shape distribution by sex and shape symmetry.

Shape classification of the condyle and mandibular fossa mold

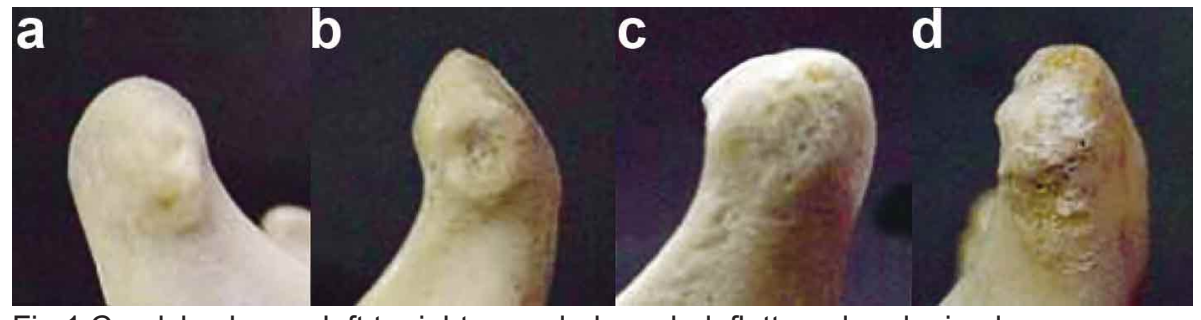

Fig.1 Condyle shapes left to right: rounded, angled, flattened and mixed.

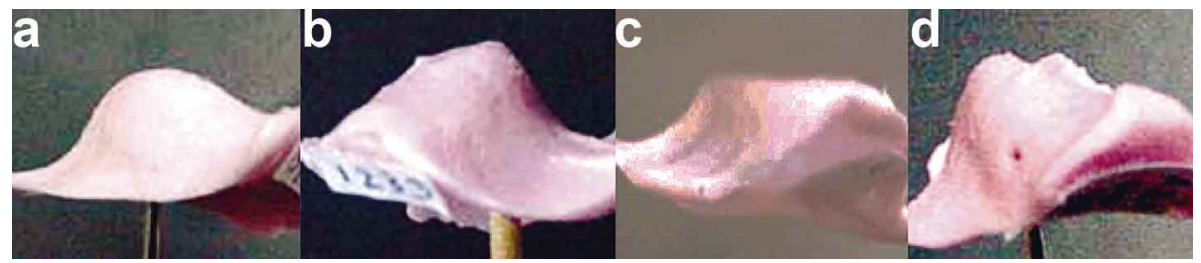

Fig.2. Fossa mold shapes left to right: rounded, angled, (flattened not found) and mixed.

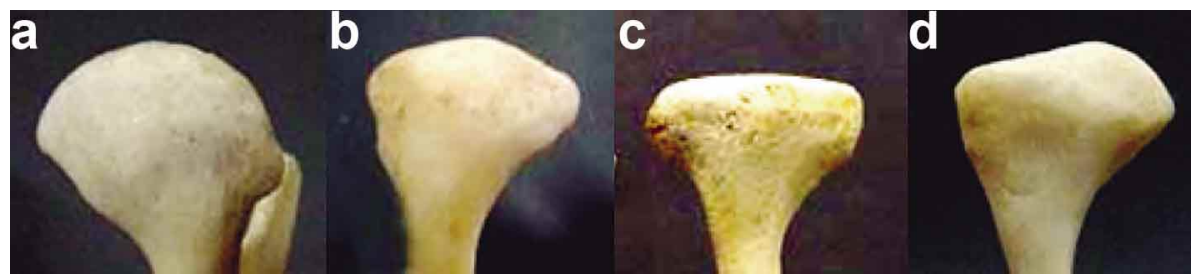

Fig.3. Condyle shapes left to right: rounded, angled, flattened and mixed.

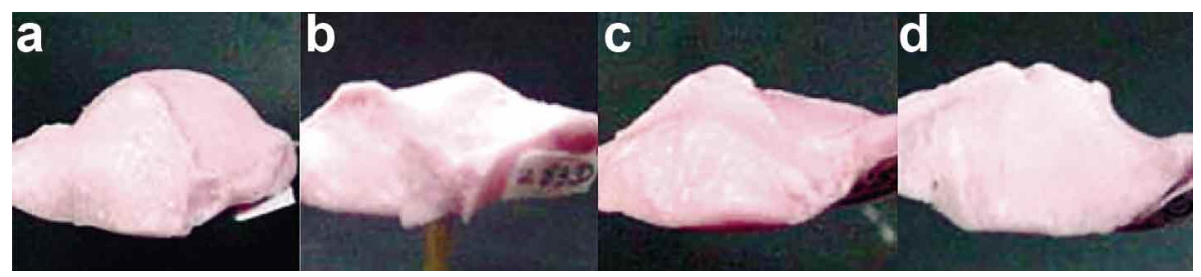

Fig.4. Fossa mold shapes left to right: rounded, angled, flattened and mixed.

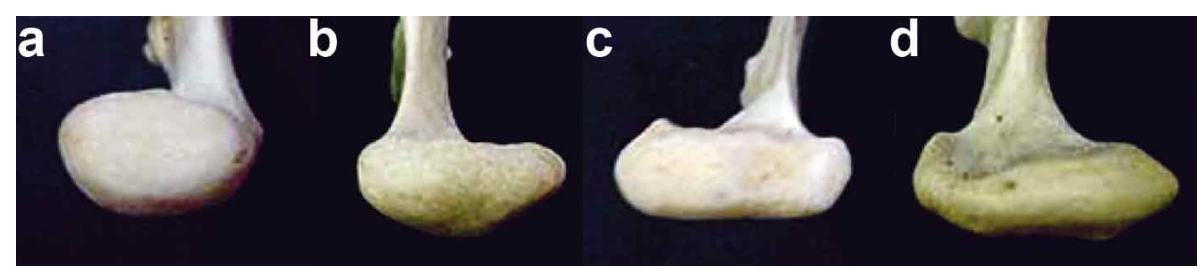

Fig.5. Condyle shapes left to right: biconvex, flattened-convex, biflattened and mixed.

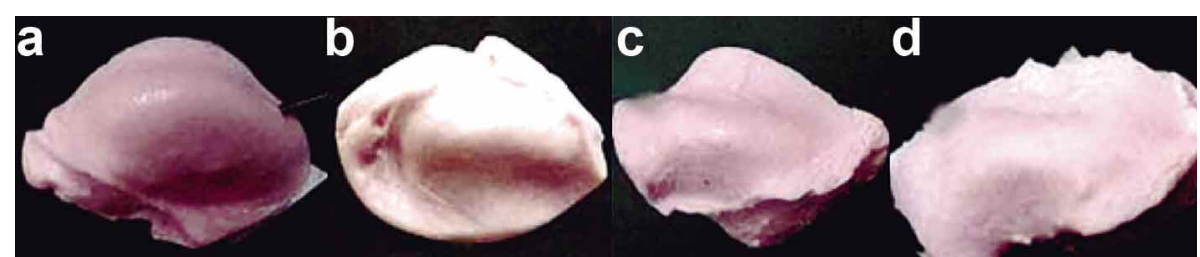

Fig.6. Shapes of the fossa mold left to right: biconvex, flattened-convex, biflattened and mixed.
Shapes were classified for the lateral, posterior and superior views.

A - Lateral view, shapes: rounded, angled, flattened and mixed (combination of the previous); condyle (Fig. 1) and fossa mold (Fig. 2).

B - Posterior view, shapes: rounded, angled, flattened and mixed (combination of the previous); condyle (Fig. 3) and fossa mold (Fig.4).

C - Superior view, shapes: biconvex, flat-convex, biflattened and mixed (combination of the previous); condyle (Fig.5) and fossa mold (Fig.6).

Results of the intra-rater (test, retest) and inter-rater analyses were not statistically significant.

Frequency of shapes. Sample distribution of condyle and mandibular fossa mold shapes is presented for the three views, lateral, posterior and superior, on the right and left $(n=100)$, in Tables I and II.

The above tables demonstrate that the rounded shape of the condyle and fossa mold was most frequent in the lateral $(57 \%$ and $66 \%$ respectively) and posterior views $(53 \%$ and $83 \%$ respectively). In the superior view, mixed shape was most common in the condyle (59\%), 
while the biconvex shape was the most frequent for the fossa mold $(46 \%)$.

Distribution between sexes. Distribution of the condyle and fossa mold shapes between sexes did not present a statistically significant difference in the three

Table I. Distribution of condyle and fossa mold shapes in the lateral and posterior views.

\begin{tabular}{lccccc}
\hline & & \multicolumn{2}{c}{ Lateral view } & \multicolumn{2}{c}{ Posterior view } \\
\cline { 3 - 6 } Shape & Side & Condyle (n) & Fossa $(\mathbf{n})$ & Condyle $(\mathbf{n})$ & Fossa $(\mathbf{n})$ \\
\hline Rounded & $\mathrm{R}$ & 29 & 33 & 28 & 39 \\
& $\mathrm{~L}$ & 28 & 33 & 25 & 44 \\
\multirow{5}{*}{ Angled } & Total & 57 & 66 & 53 & 83 \\
& $\mathrm{R}$ & 11 & 1 & 4 & 2 \\
& $\mathrm{~L}$ & 12 & 1 & 3 & 2 \\
\multirow{5}{*}{ Flattened } & Total & 23 & 2 & 7 & 4 \\
& $\mathrm{R}$ & 3 & 0 & 3 & 3 \\
& $\mathrm{~L}$ & 1 & 0 & 5 & 1 \\
& Total & 4 & 0 & 8 & 4 \\
& $\mathrm{R}$ & 7 & 16 & 15 & 6 \\
& $\mathrm{~L}$ & 9 & 16 & 17 & 3 \\
& Total & 16 & 32 & 32 & 9 \\
\hline
\end{tabular}

Table II. Distribution of condyle and fossa mold shapes in the superior view.

\begin{tabular}{lccc}
\hline Shape & Side & Condyle (n) & Fossa (n) \\
\hline Biconvex & $\mathrm{R}$ & 9 & 25 \\
& $\mathrm{~L}$ & 8 & 21 \\
Flattened-convex & Total & 17 & 46 \\
& $\mathrm{R}$ & 9 & 8 \\
Biflattened & $\mathrm{L}$ & 9 & 6 \\
& Total & 18 & 14 \\
& $\mathrm{R}$ & 5 & 0 \\
Mixed & $\mathrm{L}$ & 1 & 1 \\
& Total & 6 & 1 \\
& $\mathrm{R}$ & 27 & 17 \\
& $\mathrm{~L}$ & 32 & 22 \\
& Total & 59 & 39 \\
\hline
\end{tabular}

Table III. Distribution of symmetrical and non-symmetrical shapes in condyle and fossa mold in the lateral and posterior views ( $\mathrm{n}$ total=100 TMJ / $50 \mathrm{R}$ and $50 \mathrm{~L}$ ).

\begin{tabular}{lccccc}
\hline \multirow{2}{*}{ Shape } & \multirow{2}{*}{ Symmetry } & \multicolumn{2}{c}{ Lateral view } & \multicolumn{2}{c}{ Posterior view } \\
\cline { 2 - 6 } & & Condyle $^{*}$ & Fossa $^{* *}$ & Condyle $^{\text {No }}$ & Fossa $^{* *}$ \\
\hline Rounded & yes & 34 & 44 & 38 & 74 \\
\multirow{2}{*}{ Angled } & no & 23 & 22 & 15 & 9 \\
& yes & 12 & 0 & 2 & 0 \\
Flattened & no & 11 & 2 & 5 & 4 \\
& yes & 2 & 0 & 4 & 2 \\
Mixed & no & 2 & 0 & 4 & 2 \\
\multirow{2}{*}{ Total } & yes & 2 & 10 & 22 & 2 \\
& no & 14 & 22 & 10 & 7 \\
& yes & 50 & 54 & 66 & 78 \\
& no & 50 & 46 & 34 & 22 \\
\hline
\end{tabular}

${ }^{*}=p<0.01 ;{ }^{* *}=p<0.001 ; N S=$ not significant.

68 views, although there were distinct frequencies.

Shape symmetry. The distribution of common shapes was studied for both sides of the same skull, both in condyle and fossa mold, where the appearance of the same shape was considered symmetrical and of different shapes as nonsymmetrical, for the total of 100 TMJ (50 skulls). These findings are presented in Tables III and IV.

In the lateral view, the difference between shape symmetry and nonsymmetry was statistically significant for the condyle $(p<0.01)$ and fossa mold $(p<0.001)$. There was predominance of nonsymmetry for the mixed shape and of symmetry for the rounded shape.

In the posterior view, differences in condyle shape were not statistically significant $(0.10<p<0.20)$, while the difference in fossa mold shapes was statistically significant $(p<0.001) \quad$ with predominance of the rounded symmetrical shape.

In the superior view, differences in condyle shapes were statistically significant $(p<0.001)$ with predominance of the mixed symmetrical shape (even with right and left condyle presenting different irregularities between them), while fossa mold shapes did not show a statistically significant difference $(0.20<p<0.30)$. 
Table IV. Distribution of symmetrical and non-symmetrical shapes in condyle and fossa mold in the superior view ( $\mathrm{n}$ total $=100 \mathrm{TMJ} / 50 \mathrm{R}$ and $50 \mathrm{~L}$ ).

\begin{tabular}{lccc}
\hline Shape & Symmetry & \multicolumn{2}{c}{ Superior view } \\
\cline { 2 - 4 } & & Condyle $^{*}$ & Fossa \\
\hline Biconvex & yes & 4 & 26 \\
\multirow{3}{*}{ Flattened - Convex } & no & 13 & 20 \\
\multirow{3}{*}{ Biflattened } & yes & 4 & 4 \\
& no & 14 & 10 \\
Mixed & yes & 0 & 0 \\
\multirow{2}{*}{ Total } & no & 6 & 1 \\
& yes & 40 & 20 \\
& no & 19 & 19 \\
& yes & 48 & 50 \\
& no & 52 & 50 \\
\hline
\end{tabular}

$*=p<0.001 ; \mathrm{NS}=$ not significant.

\section{DISCUSSION}

Morphological knowledge of the temporomandibular joint (TMJ) is a tool for understanding development and growth, including phylogenetic aspects and the plastic capacity for bone remodeling characteristic of the skeleton. Topographic and shape variability found between the condyle and the mandibular fossa during development and in adulthood has stirred a need for research designed to systematize different shapes found.

Condyle shape classification has been elaborated and argued for decades (Yale et al., 1963; 1966; Christiansen et al.; Raustia \& Pyhtinen; Pandis et al.; Matsumoto \& Bolognese), but the same has not happened with fossa. There are few papers in the literature specifically describing fossa shapes and proposing a classification for them. In our search, we found only one with this purpose (Raustia \& Pyhtinen).

To study the relationship between fossa and corresponding condyle shapes, a methodology was first necessary that would allow assessing fossa shape. For this we used silicon molds obtained from the fossa impression in complete adult dry skulls, allowing comparison with condyle. A similar methodology with fossa molds was used in a paper (Katsavrias \& Dibbets, 2001), but to evaluate the joint tubercle.

Shapes were classified by looking at structure profiles in the photographic records obtained in the three spatial planes (sagittal, frontal and horizontal), which correspond to the lateral, posterior and superior views and allowed a three dimensional vision. These views have also been used by other authors, for example in a study of the condyle on the $X$ axis (lateral view), $Y$ axis (posterior view) and $Z$ axis (superior view), however, photographs were only obtained on the $\mathrm{Y}$ and $\mathrm{Z}$ axes (Yale et al., 1963; 1966). Similarly, authors using computed tomography have taken the axial (transversal) and coronal (frontal) planes to get images (Raustia \& Pyhtinen).

The denomination of condyle and fossa mold shapes followed geometric criteria. The greatest difficulty for type definition came in the superior view, in that the profile was not as evident as in the other views. The classification adopted was tested by means of intra-rater and inter-rater analyses, which yielded the reliability of the criterion used.

Distribution of condyle and fossa shapes showed greater frequency of the rounded shape in the lateral (57\% and $66 \%$ respectively) and posterior (53\% and $83 \%$ respectively) views. In the superior view, the mixed shape was most frequent in the condyle $(59 \%)$, while the biconvex shape was most common in the mandibular fossa $(46 \%)$.

The broadest comparisons possible with information from the literature concern the condyle, but there is little mention of the fossa shape.

Comparing our findings with those of two other articles (Yale et al., 1963; 1966), revealed that their classification was different from that used in this study. In the posterior view, they distinguished rounded type from convex referring to a lesser degree of curvature for rounded, both of which were included in the rounded shape in our study. The superior view was also somewhat different, in that they considered the anterior and posterior condyle borders separately, while we considered the two borders together, defining the shape. It should be noted that these same authors did not present lateral view results. In the posterior view they found 58.3\% type B (convex) and 3\% type D (rounded), compared to 53\% rounded in our sample; they found $25.2 \%$ type A (flat), compared with $8 \%$ in our study; they found $11.6 \%$ type $\mathrm{C}$ (angled) versus $7 \%$ in our findings. We found mixed shape in $32 \%$, compared to type $E$ (not included in the previous types) where they found $1.9 \%$. In the superior view, the authors made an analysis considering the shape of the anterior border separated from the posterior, which was not done in our study, and another considering the shape of the superior condyle surface. They found $59.4 \%$ type B (convex), 3.1\% type D (rounded), $25.7 \%$ type A (flat) and $11.8 \%$ type C (angled). 
In this study we found $17 \%$ biconvex, $18 \%$ flattened-convex, $6 \%$ biflattened and $59 \%$ mixed shape. We attributed the differences to methodology and classification criteria for the superior view, in light of the mixed shape not considered in the other referenced study (Yale et al., 1966).

Some authors (Christiansen et al.) have determined condyle shape by means of computed tomography using the criteria of another cited study (Yale et al., 1963) and, on the coronal plane (corresponding to our posterior view), found flattened shapes in $34 \%$, convex in $43 \%$, angled in $19 \%$ and rounded in $9 \%$. Similarly, the rounded shape was more frequent in this view, with the difference being that we did not distinguish it from convex. On the axial plane (corresponding to the superior view), they found ellipsoid shape in $40 \%$, concave convex in $40 \%$ and ovoid in $20 \%$. Our findings were not similar, in that the most common shape in the superior view was mixed.

Also by means of computed tomography, two authors (Raustia \& Pyhtinen) standardized condyle shapes, finding, on the coronal plane (corresponding to the posterior view), A1 shape (rounded or slightly convex) in $60 \%$ of patients with TMD and $50 \%$ in the control group; A2 (extensively flat - straight) in $22 \%$ and $29 \%$ respectively; $A 3$ (peak shape - inverted V) in $8 \%$ and $19 \%$ respectively; A4 (other shapes) in 10\% and $2 \%$ respectively. Once again for this view, our result was in agreement, that is, the rounded shape was most frequent.

Another classification that corresponded to the superior view, although the methodology description is not clear, was proposed by a simple radiographic study (Pandis et al.). Based on shape classification of the anterior condyle region, types were defined as flat in $30 \%$, convex in $27 \%$, triangular in $24 \%$ and concave in $19 \%$. Comparison with our results is complicated by the methodology and criteria adopted.

Two other authors (Matsumoto \& Bolognese) evaluated condyle shape in dry skulls, finding in the anterior view (our posterior): a flat or a slightly convex shape in $58.4 \%$, well rounded or convex in $25 \%$ (this was most frequent in our study), pointed in $16.6 \%$ and others in $3.1 \%$; in the superior view: oblong $60 \%$, laterally pear-shaped $20 \%$, medially pear-shaped $18.4 \%$ and rounded or oval $1.6 \%$ (our most frequent shape was mixed); in the lateral view: pointed $55 \%$, convex $31.7 \%$ and flat or slightly convex $13.3 \%$ (our most frequent shape was rounded).
Comparison with the literature concerning condyle data is limited in that, besides having different study objectives, authors also used diverse methodologies and different classification criteria.

Concerning mandibular fossa, we only found one paper (Raustia \& Pyhtinen) in the literature that described and standardized shape as we did. Other authors generally considered the shape simply as a depression in the squamous part of the temporal bone (Gardner et al., 1964; Moore \& Dalley) or as deeply concave sagittally, slightly concave transversally and wide laterally (Gray et al.). The most detailed descriptions refer to the inclination of the fossa walls (Kantomaa, 1989) or their depth which varied from 3.75 $\mathrm{mm}$ to $7.6 \mathrm{~mm}$ (Matsumoto \& Bolognese, 1995). There are authors who even included a study of the fossa shape as a research objective, but did not describe it, simply analyzing the angulation (inclination) of its articulating face and some other measures to study symmetry (Pirttiniemi \& Kantomaa).

Our data for the fossa shape and its classification in four distinct types is original and allowed comparison with different condyle shapes we defined, indicating the presence or absence of congruence.

The only study we found (Raustia \& Pyhtinen) allowing comparison showed the following fossa shape distribution analyzed in CT, on the coronal plane (our posterior view): D1 (slightly concave) in 14\% of patients with TMD and $22 \%$ in the control group; D2 (extensively flat - straight) in 4\% and 17\% respectively; D3 (highly concave - inverted $\mathrm{V}$ ) in $36 \%$ and $28 \%$ respectively; D4 (other shapes) in $46 \%$ and $33 \%$ respectively. Our findings were not similar in that in the posterior view, we found $83 \%$ rounded and this corresponds to the highly concave of these authors. They used only one view, simply placing a table with the results.

Comparing condyle and fossa mold shapes between sexes, we did not find a statistically significant difference. One article (Yale et al., 1963) reported the same finding for condyle, while another revealed a slightly higher incidence of type $A$ (flat) in women and of type B (convex) in men (Yale et al., 1966). Others considered findings for the two sexes similar (Raustia \& Pyhtinen); or found a significant difference in the height of the fossa, which was bilaterally higher in men (Pirttiniemi \& Kantomaa); or did not find significant differences between the sexes but remarked on greater wear on men's mandibles (Matsumoto \& Bolognese). 
It should be recalled that most authors did not refer to a sex variable in their sample.

The symmetry and non-symmetry of the isolated condyle and fossa shapes were analyzed in the three views, yielding significant results for both structures in the lateral view, with predominance of non-symmetry for the mixed shape and of symmetry for the rounded shape; for fossa in the posterior view, with predominance of the rounded symmetrical shape; for condyle in the superior view with predominance of the symmetrical mixed shape. It should be noted that symmetry in the mixed shape refers to the proposed classification, but not necessarily to equality.

Authors who compared sides in the sample of recent heterogeneous skulls found condyle symmetry in $77.1 \%$ of the cases; the remaining $22.9 \%$ were predominantly combinations of the flat-convex and convex-angled type (Yale et al., 1963). In another study, significant differences of condyle types were not found between sides (Christiansen et al.). However, there are authors that show temporomandibular asymmetry, where differences between sides at the base of the skull are correlated with the sagittal position of the mandibular fossa. This asymmetry should be related to unmatched functions between sides and a tendency towards asymmetrical development at the base of the skull (Pirttiniemi \& Kantomaa).

We agree that the symmetry factor should not be considered a rule in the body, because our results indicate differences according to the view and shape analyzed.

\section{CONCLUSION}

Rounded shape was the most frequent and showed the greatest symmetry. The mandibular fossa mold may or may not fit with the condyle shape. This fact does not inhibit the complex movement of the mandible, with the presence of an articulating disk that divides the cavity in two compartments not entailing functional impairment.

RIBEIRO, E. C.; SANCHES, M. L.; ALONSO, L. G. \& SMITH, R. L. Forma y simetría del cóndilo humano y fosa mandibular. Int. J. Odontostomat., 9(1):65-72, 2015.

RESUMEN: El objetivo del estudio fue determinar y clasificar la forma de la fosa mandibular y cóndilo correspondiente en diferentes tipos, relacionándolos con el sexo y la simetría en cráneos humanos adultos en perspectivas laterales, posteriores y superiores. La muestra incluyó 50 cráneos humanos de 32 hombres y 18 mujeres entre 23 a 82 años. Fueron fotografiados el cóndilo y moldes de silicona de la fosa para evaluar la forma en los tres puntos. Se clasificaron las formas, validadas por el análisis intra e inter-evaluador, la frecuencia, distribución por sexo y simetría verificada. Las formas fueron clasificadas como redondeada, en ángulo, aplanada y mixtas en las vistas lateral y posterior; y como biconvexa, convexoplana, y mixta en la vista superior. En las vistas laterales el cóndilo y la fosa redondeada fueron más frecuentes (57\% y $66 \%$, respectivamente), mientras que en la vista posterior (53\% y $83 \%)$. En la vista superior, la forma mixta presentó mayor frecuencia en el cóndilo (59\%), mientras que en la fosa la forma biconvexa (46\%) fue más común. No hubo diferencia significativa en la distribución de laforma por sexo. La misma forma (simétrica o no-simétrica) en el cóndilo lateral derecho e izquierdo y la fosa fueron evaluadas por separado, y se observaron varias combinaciones.

PALABRAS CLAVE: articulación temporomandibular, cóndilo, fosa mandibular, anatomía, forma, simetría.

\section{REFERENCES}

Christiansen, E. L.; Chan, T. T.; Thompson, J. R.; Hasso, A. N.; Hinshaw, D. B. Jr. \& Kopp, S. Computed tomography of the normal temporomandibular joint. Scand. J. Dent. Res., 95(6):499-509, 1987.

Enlow, D. H. \& Hans, M. G. Noções básicas sobre crescimento facial. São Paulo, Editora Livraria Santos, 2002.

Gardner, E.; Gray, D. J. \& O’Rahilly, R. Anatomia: Estudo regional do corpo humano. $2^{\mathrm{a}}$ ed. Rio de Janeiro, Guanabara Koogan, 1964.
Gray, H.; Williams, P. L. \& Bannister, L. H. Gray's Anatomy: the anatomical basis of medicine and surgery. $38^{\mathrm{a}} \mathrm{ed}$. New York, Churchill Livingstone, 1995. pp.567-79. 1995.

Kantomaa, T. The relation between mandibular configuration and the shape of the glenoid fossa in the human. Eur. J. Orthod., 11(1):77-81, 1989.

Katsavrias, E. G. \& Dibbets, J. M. The growth of articular eminence height during craniofacial growth period. Cranio, 19(1):13-20, 2001. 
RIBEIRO, E. C.; SANCHES, M. L.; ALONSO, L. G. \& SMITH, R. L. Shape and symmetry of human condyle and mandibular fossa. Int. J. Odontostomat., 9(1):65-72, 2015.

Matsumoto, M. A. \& Bolognese, A. M. Bone morphology of the temporomandibular joint and its relation to dental occlusion. Braz. Dent. J., 6(2):115-22, 1995.

Mongini, F. Anatomic and clinical evaluation of the relationship between the temporomandibular joint and occlusion. J. Prosthet. Dent., 38(5):539-51, 1977.

Moore, K. L. \& Dalley, A. F. Anatomia orientada para a clínica. $5^{\mathrm{a}}$ ed. Rio de Janeiro, Guanabara Koogan, 2007. pp.752-824.

Pandis, N.; Karpac, J.; Trevino, R. \& Williams, B. A radiographic study of condyle position at various depths of cut in dry skulls with axially corrected lateral tomograms. Am. J. Orthod. Dentofacial Orthop., 100(2):116-22, 1991.

Pirttiniemi, P. \& Kantomaa, T. Relation of glenoid fossa morphology to mandibulofacial asymmetry, studied in dry human Lapp skulls. Acta Odontol. Scand., 50(4):235-43, 1992.

Raustia, A. M. \& Pyhtinen, J. Morphology of the condyles and mandibular fossa as seen by computed tomography. J. Prosthet. Dent., 63(1):77-82, 1990.

Siegel, S. \& Castellan Jr., N. J. Estatística não-paramétrica para ciências do comportamento. $2^{a}$ ed. Porto Alegre, Artmed, 2006.

Takenoshita, Y. Development with age of the human mandibular condyle. Part I: Gross anatomy and inner architecture. Dentomaxillofac. Radiol., 11(1):5-15, 1982.

Yale, S. H.; Allison, B. D. \& Hauptfuehrer, J. D. An epidemiological assessment of mandibular condyle morphology. Oral Surg. Oral Med. Oral. Pathol., 21(2):169-77, 1966.

Yale, S. H.; Ceballos, M.; Kresnoff, C. S. \& Hauptfuehrer, J. D. Some observations on the classification of mandibular condyle types. Oral Surg. Oral Med. Oral Pathol., 16:5727, 1963.

Yale, S. H. Radiographic evaluation of the temporomandibular joint. J. Am. Dent. Assoc., 79(1):102-7, 1969.
Correspondence to:

Eduardo C. Ribeiro, PhD

Department of Morphology - Anatomy

Universidade Federal de São Paulo

Rua Botucatu, 740

São Paulo

SP 04023-900

BRAZIL

Email: eduribeiro.morf@epm.br

Received: 03-05-2014

Accepted: 06-03-2015 